\title{
O "ADEUS AO PROLETARIADO" DE GORZ, VINTE ANOS DEPOIS
}

\author{
JOSUÉ PEREIRA DA SILVA
}

\begin{abstract}
O principal objetivo deste artigo é retomar uma questão, entre as inúmeras sugeridas pelo livro de Gorz, que está no centro das preocupações de todos nós nessa virada de milênio, ou seja, os limites do trabalho como meio de integração social.

No mundo moderno, capitalista, o trabalho tem sido o principal meio de integração social dos indivíduos e, por isso mesmo, o veículo para a cidadania social. Nas últimas décadạs, porém, com as rápidas mudanças tecnológicas e o persistente desemprego em grande parte decorrente do uso de novas tecnologias, surgiu um grande número de publicações (livros e artigos) falando no fim do trabalho (Aznar, 1990; Eder, 1992; Dahrendorf, 1992; Kurz, 1992; König, 1994; Rifkin, 1995; Méda, 1995; Bidet e Texier (org.), 1995; Perret, 1995; Castel, 1995; Forrester, 1997; Schnapper, 1997). Embora essas publicações nem sempre sustentem a mesma tese a respeito do assunto, elas contribuem para reavivar o interesse pelo tema central do livro de André Gorz.
\end{abstract}

\section{I}

Escrito na forma de ensaio e publicado em 1980, Adeus ao proletariado é o décimo primeiro e, certemente, o mais famoso entre os livros de André Gorz. Considerando o tema central e o próprio título do livro, talvez seja desnecessário escrever que se trata de um livro polêmico; creio, no entanto, que não é demais chamar a atenção para este aspecto do livro, pois muito de sua importância deve-se à natureza polêmica de suas principais teses. E é justamente isto, ao meu ver, que justifica um artigo como este no momento que o livro está completando vinte anos de publicação. 
A tese básica do livro, em torno da qual todas as outras se desenvolvem, refere-se à abolição do trabalho: "O marxismo está em crise porque há uma crise do movimento operário" (Gorz, 1980:13). E o movimento operário está em crise porque "entramos na era da abolição do trabalho" (Gorz, 1981:1541). A abolição do trabalho aparece portanto como a chave para se compreender (e explicar) tanto a crise do movimento operário quanto a crise do marxismo.

Por esta razão, o tema da abolição do trabalho nos escritos de André Gorz será o objeto deste artigo. E para discutí-lo, além de Adeus ao proletariado, recorrerei também a outros textos do mesmo autor.

$\mathrm{Na}$ análise Gorz, apresentada a seguir, a dupla crise - do marxismo e do movimento operário - decorre da ruptura entre o desenvolvimento das forças produtivas e o aprofundamento das contradições de classe. Essa ruptura é atribuída ao fato de o capitalismo ter aprendido, durante as décadas que antecederam a publicação do mencionado livro, a administrar suas crises de forma a prevenir um colapso do sistema, a despeito de as relações de produção continuarem as mesmas.

Para o marxismo, o significado dessa ruptura foi profundo, uma vez que a própria idéia de socialismo científico supunha como condições, primeiro, que a revolução socialista seria a tarefa de uma classe social (o proletariado), que englobaria a maioria dos produtores sociais; e, segundo, que a essência dessa classe seria a impossibilidade consciente dela aceitar sua realidade social como uma classe (Gorz, 1980; 1988).

Foi com base nessas condições, segundo Gorz, que a teoria marxista da revolução proletária sustentou a tese segundo a qual "o desenvolvimento das forças produtivas engendra a base material do socialismo" (Gorz, 1980:14); e que esse desenvolvimento "faz surgir a base social do socialismo, a saber: uma classe operária capaz de se apropriar coletivamente e de gerir a totalidade das forças produtivas cujo desenvolvimento a fez nascer" (Gorz, 1980:14). Ou seja, a força do marxismo como um instrumento analítico e intelectual, ou mesmo revolucionário, encontrava suporte nessas contradições de classe.

Mas, segundo Gorz, a conexão entre estes dois postulados não foi confirmada pela realidade. Em primeiro lugar, porque a chamada base material para o socialismo não pode ser derivada do desenvolvimento das forças capitalistas de produção, já que estas últimas funcionam apenas de acordo com a lógica da racionalidade capitalista. Assim, ao invés de prover a base material para uma sociedade socialista, elas tornam-se um obstáculo para esta última. Portanto, seria necessário fazer uma reconversão com- 
pleta de tais forças produtivas para adaptá-las às necessidades de uma sociedade socialista. Em segundo lugar, porque o desenvolvimento das forças produtivas capitalistas não funciona de forma a permitir uma apropriação coletiva direta pelo trabalhador coletivo, isto é, pelo proletariado. Ou seja, o desenvolvimento capitalista criou uma classe operária que não tem capacidade para administrar os meios de produção e cujos interesses não necessariamente coincidem com a racionalidade socialista.

Daí sua conclusão de que a chave para um diagnóstico da crise do marxismo está na dissociação entre o desenvolvimento das forças produtivas e o crescimento das contradições de classe.

\section{II}

Adeus ao proletariado é de certa forma o resultado de quase uma década de reflexão de seu autor sobre o futuro do proletariado na sociedade contemporânea e representa uma ruptura com suas concepções teóricas e políticas anteriores à década de 1970, nas quais toda esperança de transformação da sociedade estava depositada no potencial revolucionário do proletariado.

Uma análise dos escritos de Gorz publicados antes de Adeus ao proletariado indica que foi por volta da metade dessa década que ocorreu esse ponto de inflexão em sua teoria. Até o início dos anos setenta, por exemplo, o tema da alienação aparecia como uma preocupação central de seus escritos. Nessa época, a alienação é discutida, de um lado, como um problema do indivíduo, em sua relação com a história pregressa, com o corpo, com o meio ambiente e com a sociedade (Gorz, 1977); de outro, como um problema sociológico, onde o foco da análise são as classes sociais (Gorz, 1959). Em ambos os casos, seguindo a tradição fenomenológica, a problemática da consciência é fundamental, só que no primeiro é o indivíduo isolado que se debate na busca da consciência da sua situação como indivíduo num mundo alienado, enquanto no segundo quem luta para adquirir consciência é a classe social, mais especificamente a classe operária.

Inspirado sobretudo em Marx e Sartre, Gorz transformou o conceito de alienação num importante instrumento de crítica social e, a partir dele, elaborou uma estratégia política que ele acreditava capaz de tirar a classe operária do impasse criado pelos sucessos do "Welfare State" keynesiano (Gorz, 1964). Para Gorz, o problema da alienação, particularmente no local de trabalho, na fábrica, era o eixo em torno do qual se devia construir uma estratégia de reformas revolucionárias que conduzisse à transfor- 
mação social (Gorz, 1967; 1969). Isto porque no contexto das sociedades industriais desenvolvidas, onde o padrão de vida da classe operária estava acima da linha de miséria, a luta contra a mesma não podia mais ser tomada como uma fonte da qual brotaria automaticamente a consciência de classe.

Nessa teoria não existe a possibilidade de eliminar a alienação em uma esfera da sociedade sem se fazer o mesmo em outras. Por isso Gorz liga a alienação na produção à alienação no consumo. No entanto, ele elege a esfera da produção como o ponto de partida privilegiado a partir do qual se deveria iniciar a luta contra a alienação. Ora, essa primazia atribuída por ele à esfera da produção está relacionada ao lugar determinante que a categoria trabalho ocupava na estrutura de sua teoria, ao mesmo tempo que revela a extensão de seu apego ao chamado paradigma do trabalho. Pode-se dizer, portanto, que a teoria de Gorz nesse período baseava-se nos dois seguintes pressupostos interligados: primeiro, a sociedade podia ser vista através do modelo da fábrica; e, segundo, que a classe operária era o único sujeito capaz de liderar uma transformação social. Esta é a razão pela qual o local de trabalho (a fábrica) aparecia não só como a arena mais importante na luta contra o capital pelo controle do processo de trabalho, mas também como o espaço onde o fim da alienação podia ser inicialmente viabilizado (Silva, 1993).

A partir do final dos anos setenta Gorz abandona esse modelo de sociedade unificado em torno da categoria trabalho e passa a postular um modelo de sociedade baseada em duas esferas diferenciadas e autônomas e no qual o trabalho não é mais uma categoria hegemônica, nem o proletariado o único sujeito capaz de liderar uma transformação social. Na verdade, essa concepção de sociedade baseada no modelo do trabalho começa a ser abandonada já na metade dos anos 70 com a publicação de alguns escritos sobre ecologia (Gorz, 1978), mas é somente em $1980 \mathrm{com}$ Adeus ao Proletariado que essa mudança de concepção ganha forma definitiva (Silva, 1993).

As razões que fundamentam essa mudança de concepção são basicamente duas. A primeira é o que ele chama de divisão macro-social do trabalho que impede o proletariado, individual ou coletivamente, de se apropriar de um aparato social produtivo caracterizado por instituições complexas e sem nenhuma transparência (Gorz, 1980). O reconhecimento de que a divisão do trabalho não pode ser eliminada significa admitir que a alienação não pode ser também eliminada, já que, segundo o próprio Gorz, a última resulta da primeira (Gorz, 1973). 
A segunda é a chamada revolução microeletrônica, que, para ele, tende a eliminar todo trabalho que envolve um contato direto com a matéria, assim como a própria classe operária: "A revolução microeletrônica inaugura a era de abolição do trabalho. E essa última deve ser compreendida num duplo sentido: a) a quantidade de trabalho necessário decresce rapidamente até se tornar marginal na maior parte das produções materiais e das atividades de organização; b) o trabalho não implica mais um face a face do trabalhador com a matéria. A transformação desta não resulta de uma atividade imediata completa e soberana" (Gorz, 1983:73).

Enquanto a primeira representa uma revisão de suas posições teóricas anteriores, a segunda resulta de uma análise das mudanças ocorridas na esfera da produção, durante as últimas décadas. Porém, em ambos os casos, o trabalho aparece como pano de fundo comum. Por trás dessa mudança de perspectiva na sua trajetória intelectual está, portanto, uma reavaliação do conceito de trabalho.' E esta redefinição da noção de trabalho que aparece nos escritos de Gorz a partir do final da década de setenta é, ao meu ver, de grande importância para se compreender o debate atual sobre a crise da sociedade de trabalho (Silva, 1995).

\section{III}

Para André Gorz, o trabalho no sentido que nós o entendemos hoje é uma invenção moderna, cuja generalização ocorreu somente com o advento do industrialismo. Boa parte da inspiração de Gorz, ao discutir o conceito de trabalho, encontra-se em Hannah Arendt (1958), sobretudo na interessante distinção que ela faz entre "work" e "labor"."

Para Arendt, "labor" (isto é, trabalho) é a atividade básica que combina necessidade e futilidade (no sentido de efêmero). Necessidade porque corresponde ao processo biológico do corpo humano do qual depende a perpetuação da vida. É uma atividade que o ser humano não pode evitar se quiser continuar vivo e perpetuar a espécie. Futilidade porque é a atividade que se esgota no próprio processo vital, não deixando traço de per-

\footnotetext{
I Em seus escritos anteriorès, não eta evidente esta preocupação conceitual em relação à noção de trabalho.

2 Na edição brasileira de seu livro The Human Condition, os termos "work" e "labor" foram traduzidos, ao meu ver imprecisamente, como respectivamente trabalho e labor. A tradução é imprecisa porque no português o termo trabalho (do francês "travail") corresponde originalmente ao que Arendt chama de "labor" e não ao que ela chama de "work", cujo correspondente seria obra (Arendt, 1958: 48, n.39).
} 
manência. "Work" (isto é, obra), por sua vez, é uma atividade inerentemente solitária, que corresponde ao não natural da existência humana e que não é intrínseco ao ciclo vital da espécie. É uma atividade humana que combina permanência e liberdade, produzindo coisas para uso que vai além do mero consumo (Arendt, 1958).

O conceito moderno de trabalho, do qual fala André Gorz, é resultado de uma simbiose dessas duas atividades, mas não se confunde com nenhuma das delas. Sua característica essencial é o fato de ser uma ativividade que se exerce na esfera pública, onde é definido e reconhecido por outros como uma atividade útil, fazendo jus a um pagamento na forma de salário. Ou seja, o trabalho no sentido moderno é o trabalho assalariado (Gorz, 1988).

Com o capitalismo industrial, o trabalho assalariado tornou-se o meio através do qual os indivíduos adquirem existência e identidade social pelo exercício de uma profissão. A transformação do trabalho assalariado no mais importante fator de integração social permitiu, por sua vez, que a sociedade industrial não só se distinguisse das outras formações sociais previamente existentes, mas também que se auto-definisse como uma sociedade de trabalhadores (Arendt, 1958; Offe, 1985).

Para Gorz, no entanto, essa forma de trabalho assalariado sobre o qual se funda a coesão e a cidadania sociais não pode ser redutível ao 'trabalho' no sentido antropológico, já que esse último, ao invés de ser concebido como um meio de integração social, sempre funcionou, ao contrário, como critério para excluir os indivíduos da esfera pública (Gorz, 1988:26).

Gorz afirma a esse respeito que, entre os gregos antigos, os homens que permaneciam presos ao reino da necessidade, submetendo-se às necessidades do corpo, não eram considerados capazes de conduta moral. A liberdade (o reino humano), ou a capacidade de pertencer à esfera pública, somente seria possível para eles depois de superar o constrangimento das necessidades corporais, isto é, o reino da necessidade. No mundo antigo, as atividades econômicas ocorriam geralmente no interior dos domicílios, um espaço privado no qual a atividade do "labor" era exercida. Assim, o "labor" associado à necessidade econômica pertencia à esfera privada, enquanto a liberdade era concebida como pertencente à esfera pública, política.

No mundo moderno, capitalista, as atividades econômicas passaram a ser exercidas na esfera pública e a ser mediadas pelo mercado. Isso implicou uma racionalização econômica do trabalho, com a transformação da força de trabalho em uma mercadoria (Marx, 1967), ainda que fictícia (Polanyi, 1948). É só então, segundo Gorz, que dá para se falar em trabatho no sentido moderno. Daí sua afirmação de que a concepção moderna 
de trabalho apareceu somente durante o século XVIII com o advento do capitalismo manufatureiro.

Para Gorz, antes dessa época o termo trabalho referia-se principalmente à produção de bens de consumo e serviços, nos quais servos e diaristas labutavam diariamente numa atividade que se auto-consumia. No que se refere aos artesãos, que produziam objetos duráveis, Gorz afirma que eles não 'trabalhavam' (no sentido de "labor"), mas sim 'obravam' (no sentido de work). E na 'obra', eles podiam eventualmente utilizar o 'labor' de homens não qualificados para desempenhar tarefas grosseiras, pouco qualificadas (Gorz, 1988:28-29).

Gorz afirma também que não foi uma tarefa fácil fazer com que o trabalho se tornasse uma atividade economicamente racional. Mesmo durante o século XIX, quando o capitalismo industrial já tinha se tornado uma realidade, o domínio desse tipo de racionalidade ainda não era exclusivo (Polanyi, 1948). A principal dificuldade neste sentido foi a indisposição dos trabalhadores em aceitar a disciplina de fábrica, que para eles significava trabalhar diariamente em tempo integral. A burguesia conseguiu resolver esse problema pagando "salários tão baixos que era necessário penar uma boa dezena de horas por dia ao longo da semana para se ganhar a subsistência" (Gorz, 1988:35; Topalov, 1987).

A racionalização econômica do trabalho significou também "uma revolução, uma subversão do modo de vida, dos valores, das relações sociais e das relações com a natureza, a invenção no sentido pleno do termo de alguma coisa que até então jamais havia existido. A atividade produtiva fôra esvaziada de seu sentido, de suas motivações e de seu objeto para se tornar meio de ganhar um salário. Ela deixou de fazer parte da vida para se tornar o meio de 'ganhar sua vida'. O tempo de trabalho e o tempo de viver foram separados; o trabalho, seus instrumentos, seus produtos adquiriram uma realidade separada dequela do trabalhador e passaram a depender de decisões estranhas. A satisfação 'do obrar' em comum e o prazer de 'fazer' foram suprimidos em benefício somente daquilo que podia fazer dinheiro" (Gorz, 1988:36).

Foi essa revolução nos costumes, provocada pela racionalização econômica do trabalho, que possibilitou, segundo Gorz, o aparecimento do "indíviduo que, alienado em seu trabalho, o será também necessariamente, em seus consumos e, finalmente, em suas necessidades" (Gorz, 1988:37). Isso porque, com a monetarização do trabalho, os limites quantitativos para fazer dinheiro e para consumir mercadorias desaparaceram por completo. 
Gorz define racionalidade econômica como uma forma particular de racionalidade cognitiva instrumental. Para ele, a racionalização econômica começa com a contabilidade e o cálculo que são concebidos como a forma quintessencial de racionalização reificante. Para que exista racionalidade econômica, é necessário antes de tudo que o trabalho exercido seja concebido como um meio para produzir mercadorias, ao invés de bens para auto-consumo; e, além disso, que as mercadorias sejam produzidas para a troca num mercado livre, onde diferentes produtores se enfrentam como concorrentes (Gorz, 1988:139).

É fato, segundo Gorz, que a natureza das necessidades humanas tem sido, historicamente, um obstáculo ao desenvolvimento da racionalidade econômica, como é demonstrado pela dificuldade dos primeiros industriais em organizar a produção com base no trabalho em tempo integral. Tal dificuldade se explica porque "a racionalidade econômica não se aplica quando o indivíduo é livre para determinar ele próprio o nível de suas necessidades e o nível do seu esforço" (Gorz, 1988:141-2). Em situações onde as pessoas eram livres para decidir sobre suas necessidades e seus esforços, elas tendiam espontaneamente a limitar ambos - seus esforços e suas necessidades - a um certo nível, quando sentiam que tinham o bastante. Assim, mesmo considerando que esse nível varia historicamente, em tais situações é "a categoria do suficiente que regula o equilíbrio entre o nível de satisfação e o volume de trabalho para si" (Gorz, 1988:142). Para Gorz, essa última categoria, que - do ponto vista cultural - é central para qualquer sociedade tradicional, "não é uma categoria econômica: é uma categoria cultural ou existencial" (Gorz, 1988:142).

Mas essa situação mudou progressivamente. À medida que o cálculo contábil passou a substituir a ordem religiosa tradicional, a racionalidade econômica conseguiu emancipar as pessoas da tutela religiosa externa e proveu-as com uma nova ordem. $\mathrm{O}$ arcabouço dessa nova ordem derivou de leis objetivas do universo e sua autoridade não era dependente da vontade humana. Assim, liberada dos velhos constrangimentos, a atividade econômica se tornou uma busca incansável de lucro e a acumulação de riqueza se tornou "a prova da justeza dos cálculos" (Gorz, 1988:143).

O importante a reter em tudo isso, segundo Gorz, é que o "espírito do capitalismo' cortou o vínculo entre trabalho e vida (Weber, 1958). Para Gorz, a racionalidade econômica, baseada na quantificação e no cálculo, conseguiu eliminar todo critério que levava as pessoas a estarem satisfeitas com aquilo que tinham e a substituirem o velho princípio do 'o que tenho me é suficiente' pelo novo princípio do 'quanto mais tenho mais quero'. 
A força da racionalidade econômica, continua Gorz, reside basicamente na aparente objetividade de seus critérios de julgamento baseados no cálculo. Isso quer dizer que o cálculo é "uma técnica que dispensa o sujeito de dar sentido à decisão e de assumi-la como sua: é o próprio cálculo que decide" (Gorz, 1988:160). Mas, para Gorz, o cálculo econômico não é capaz de auto-reflexão; ele não pode por si só dar sentido às ações que ele sustenta. Por isso mesmo, os limites à expansão da racionalidade econômica vêm necessariamente de fora dela através de julgamentos de valor baseados em princípios éticos. Essa é também a razão pela qual Gorz critica o projeto neo-liberal, que prega liberdade ilimitada para a racionalidade econômica.

Da análise acima decorre a necessidade de uma definição mais precisa do que Gorz chama de trabalho no sentido economicamente racional. Para ele, um tal esclarecimento conceitual permite separar as atividades que podem ser subordinadas à racionalidade econômica daquelas que não devem ser subordinadas a esse tipo de racionalidade.

Gorz desenvolve seus argumentos sobre a necessidade de estabelecer limites à racionalidade econômica afirmando que em Marx a noção de trabalho é tão indiferenciada que, em seus escritos, a atividade de um trabalhador industrial aparece frequentemente assemelhada, por exemplo, à atividade de um compositor.

Para Gorz, isto se torna problemático na medida em que muitos ideólogos contemporâneos — no esforço de demonstrar que o modelo de uma 'sociedade baseada no trabalho' ainda não está obsoleto — têm levado mais longe ainda essa indiferenciada noção de trabalho. Para alguns desses ideólogos, afirma Gorz, "as atividades do técnico, do policial, do biscateiro, do entregador de croissants quentes a domicílio, da mãe, do engraxate, do padre, da prostituta, etc., tudo isso é 'trabalho', tudo isso tem sua utilidade social e tudo isso merece ser remunerado de uma ou outra maneira" (Gorz, 1988:168).

Gorz não aceita um conceito de trabalho que incorpore todas essas atividades. Para ele, uma noção de trabalho tão ampla conduziria ao erro, que "consiste em remunerar as atividades que não tem fins comerciais e em sujeitar à lógica do rendimento atos que só estarão de conformidade com seu significado se o tempo que eles consomem não for levado em conta" (Gorz, 1988:170-1). O simples fato de ser socialmente útil, sustenta Gorz, não é suficiente para caracterizar uma atividade como trabalho. Além do mais, acrescenta ele, é necessario ir além da simples definição de trabalho economicamente racional e definir também seus critérios de aplicabilidade. 
Para Gorz, o trabalho no sentido economicamente racional deve preencher os quatro critérios seguintes: a) criar valor de uso; b) ter em vista a troca comercial; c) ser exercido na esfera pública; d) ter o tempo como critério de medida de produtividade. Uma atividade só pode ser considerada trabalho economicamente racional se ela preencher todas essas quatro condições ao mesmo tempo. Portanto, "não é suficiente que uma atividade seja empreendida tendo em vista a troca comercial... para que ela seja considerada trabalho no sentido econômico" (Gorz, 1988:173).

Com o objetivo de delimitar melhor a definição, ele analisa diversas atividades para ver até que ponto elas carecem de pelo menos uma das quatro condições necessárias para definir trabalho no sentido economicamente racional. Ele divide essas atividades em dois grupos: mercantis (atividades exercidas com o objetivo de remuneração) e não-mercantis (atividades para as quais a remuneração não é o objetivo primeiro).

O grupo das atividades mercantis é então subdividido, segundo a natureza de cada atividade, em cinco subgrupos, que são classificados em termos dos quatro critérios mencionados acima. Os subgrupos são assim denominados: trabalho no sentido econômico como emancipação, trabatho do servidor, funções, cuidados e assistência, prostituição e maternidade, funções maternais e mães substitutas. Depois de analisar as atividades desses subgrupos, ele conclui que somente o primeiro subgrupo, o do trabalho no sentido econômico como emancipação, preenche todos os quatro critérios necessários para a definição satisfatória de trabalho. Em outras palavras, ele "cria valor de uso", é executado "para ser trocado como mercadoria", é exercido "na esfera pública" e, finalmente, sua produtividade é mensurável em termos de uma quantidade de tempo.

Por outro lado, nenhum dos outros quatro subgrupos preenche todas as condições requeridas para ser definido como trabalho economicante racional. Assim, o segundo subgrupo, o trabalho do servidor, preenche todas as condições, com exceção da condição "a". Ou seja, ele não cria valor de uso (condição a) e não pode portanto ser caracterizado como trabalho no sentido economicamente racional. $O$ terceiro subgrupo, funções, cuidados e assistência, carece da condição "d", ou seja, eles não podem usar uma quantidade determinada de tempo como critério de medida de produtividade. Em relação à prostituição, o quarto subgrupo, Gorz afirma que ela não pode ser considerada trabalho no sentido economicamente racional porque, entre outras coisas, ela carece da condição 'c', isto é, não é exercida na esfera pública. Finalmente, as atividades lis- 
tadas como maternidade, função maternal, mães substitutas não preenchem nenhuma das quatro condições acima mencionadas.

Resta falar ainda do grupo de "atividades não-mercantis", que é, por sua vez, dividido em dois subgrupos. O primeiro subgrupo é o do "trabalho para si", definido como "aquela produção de valor de uso na qual nós somos os próprios artifices e os únicos destinatários" (Gorz, 1988:191). O segundo subgrupo é o das "atividades autônomas", as quais, segundo Gorz, são formadas pelas "atividades sem necessidade nem utilidade alguma, que são elas mesmas seu próprio fïm" (Gorz, 1988:191). Obviamente, nenhuma das atividades desses dois últimos subgrupos pode ser definida como trabalho no sentido economicamente racional.

Com base na análise acima, não é difícil perceber que, quando fala em abolição do trabalho, Gorz está se referindo especificamente ao subgrupo de atividade denominado trabalho no sentido econômico como emancipação: "O trabalho que desaparece é o trabalho abstrato, o trabalho em si, mensurável, quantificável, destacável da pessoa que o 'fornece', suscetível de ser comprado e vendido no 'mercado de trabalho'. Em suma é o trabalho monetarizável ou trabalho-mercadoria, que foi inventado e imposto à força e ao custo de muito sofrimento pelo capitalismo manufatureiro a partir do fim do século XVIII" (Gorz, 1997:95).

\section{IV}

Para Gorz, é incontestável que as sociedades industriais estão produzindo crescentes quantidades de riqueza com quantidades decrescentes de trabalho. E a não compreensão dessa nova realidade tem contribuído tanto para alimentar a confusão entre direito ao trabalho, direito a ter um emprego e direito a uma renda quanto para que o problema de desemprego seja considerado um fenômeno acidental e temporário na vida do desempregado. Isto tem levado alguns estudiosos a sustentar a tese de que uma nova solidariedade entre, de um lado, os trabalhadores em tempo integral e, de outro, os desempregados e os trabalhadores casuais poderia oferecer uma saída para essa situação. Mas, segundo Gorz, essa nova solidariedade só é possível se houver um rompimento com a utopia do trabaIho. Para ele, esta última tem contribuído muito para ocultar o fato de que "a economia não tem mais necessidade... do trabalho de todos. E que, por consequência, a 'sociedade do trabalho' está caduca: o trabalho não pode mais servir de fundamento à integração social" (Gorz, 1988:93). Por isso mesmo, afirma Gorz, o único projeto de sociedade capaz de reter o con- 
teúdo ético da utopia socialista é uma sociedade de tempo livre: "O mesmo trabalho que... é corvéia quando efetuado cotidianamente e em tempo integral, torna-se um tempo entre outros quando, distribuído ao conjunto da população, ocupa apenas quinze minutos ao dia" (Gorz, 1980: 146).

E mesmo reconhecendo que não há nenhum sujeito social capaz de dar suporte a uma política de redução generalizada do tempo de redução trabalho em toda a sociedade, ele acredita que este é o único meio de dar algum sentido à revolução tecnológica ora em curso.

O fato de o tempo livre tender a se tornar mais importante que o tempo de trabalho não significa que este último possa ser completamente eliminado nem que a esfera da heteronomia (ou necessidade) venha a desaparecer. Portanto, mesmo ocupando um lugar residual na vida dos indivíduos, essa esfera da heteronomia nunca será totalmente eliminada. A ênfase no indivíduo como um requisito fundamental para a existência da esfera da autonomia não significa pois uma negação da outra esfera da sociedade: "a moralização não exige necessariamente a supressão da esfera da heteronomia; ela exige apenas sua subordinação à esfera da autonomia" (Gorz, 1980:134).

No esquema conceitual de Gorz, a esfera da heteronomia inclui duas atividades heterônomas diferentes: uma que é formada pelos requerimentos necessários à produção social (aparelho de produção) e outra que se refere ao funcionamento da sociedade como um sistema (aparelho de administração). Partindo portanto de uma concepção de sociedade definida como uma dualidade formada por duas esferas separadas - a esfera da autonomia (ou liberdade) e a esfera da heteronomia (ou necessidade) - Gorz argumenta, seguindo Marx, que o reino da liberdade será conquistado através da "redução da duração do trabalho e dos esforços requeridos pela produção do necessário" (Gorz, 1980:135). A convivência necessária entre essas duas esferas da sociedade resulta, de um lado, da impossibilidade de eliminar completamente o trabalho socialmente necessário e, de outro lado, da suposição de que esse último seria menos alienante se reduzido a uma quantidade residual de tempo. Assim, a restrição da racionalidade econômica através da redução do tempo de trabalho é entendida como um importante passo nessa direção.

A elucidação conceitual da noção de trabalho, iniciada por Gorz em Adeus ao Proletariado e desenvolvida em seus escritos a partir de 1980, constitui-se, ao meu ver, numa importante contribuição para o debate contemporâneo. Na medida em que grande parte da literatura sobre esse debate 
fala em trabalho num sentido muito genérico, não se preocupando em precisar conceitualmente os termos da discussão, o empreendimento de André Gorz contribui para preencher uma lacuna, ajudando a unificar a linguagem do debate.

JOSUÉ PEREIRA DA SILVA é professor de Sociologia no IFCH da UNICAMP

\section{REFERÊNCIAS BIBLIOGRÁFICAS}

ARENDT, Hannah (1958) - The Human Condition. Chicago, University of Chicago Press. AZNAR, Guy (1990) - Le travail, c'est fini. Paris, Pierre Belfon. BIDET, J. e TEXIER, J. (org./ 1995) - La crise du travail. Paris, PUF.

CASTEL, Robert (1995) - Les métamorphoses de la question sociale. Paris, Fayard. DAHRENDORF, Ralf (1992) - O Conflito Industrial Moderno. Sño Paulo, Zahar/Edusp. EDER, Klaus (1992) - "Culture and Crisis: Making Sense of the Crisis of the Work Society". Theory of Culture, Richard Munch and Neil J. Smelser (editors), Berkeley, University of California Press.

FORRESTER, Viviane (1997) - O Horror Econômico. São Paulo, Ed. UNESP

GORZ, André (1959) - La Morale de L'Histoire. Paris, Editions du Seuil. (1964) - Stratégie Ouvrière et Néocapitalisme Paris, Editions du Seuil. (1967) - Le Socialisme Difficile. Paris, Editions du Seuil. (1969) - Réforme et Révolution. Paris, Editions du Seuil. (1973) - Critique de la division du travail. Paris, Editions du Seuil. (1977) - Fondements pour une morale. Paris, Editions Galilée. . (1978) - Ecologie et Politique (augmentée). Paris, Editions du Seuil. (1980) - Adieux cu Prolétariat. Au de-là du socialisme. Paris, Editions Galilée. (1981) - "Neuf thèses pour une gauche future". Les Temps Modernes, 416, pp.1541-1554. (1983) - Les Chemins du Paradis. L'agonie du capital. Paris, Editions Galilée. (1988) - Métamorphoses du Travail. Quête du sens. Critique de la raison économique. Paris, Editions Galilée. (1997) - Misères du présent. Richesse du possible. Paris, Editions Galilée.

KONIG, Helmut (1994) - "A crise da sociedade de trabalho e o futuro do trabalho: crítica de um debate atual". Teorias de Educaşão do Ilumumismo, Conceitos de Traballho e do Sujeito, Werner Markert (org.), RJ, Tempo Brasileiro.

KURZ, Robert (1992) - O Colapso da Modernizaçăo. Rio de Janeiro, Paz e Terra. MARX, Karl (1967). Capital. New York, International Publishers.

MÉDA, Dominique (1995) - Le travail. Une valeur en voie de disparition. Paris, Aubier. OFFE, Claus (1985) - Disorganized Capitalism. Cambridge, Ma, MIT Press. PERRET, Bernard (1995) - L'Avenir du Travail. Paris, Seuil. POLANY1, Karl (1948) - The Great Transformation. Boston, Beacon Press. RIFKIN, Jeremy (1995) - The End of Work. New York, G.P. Putnam's Sons. SCHNAPPER, Dominique (1997) - Contre la fin du travail. Paris, Ed. Textuel. 
SILVA, Josué Pereira da (1993) - "Alienation, Work and Utopia: A Study of the Thought of André Gorz". these de PhD, New York, The Graduate Faculty, New School for Social Research.

(1995) - "A crise da sociedade do trabalho em debate", Lua Nova, 35, pp.167181.

TOPALOV, Christian (1987) - "Invention du chômage et politiques sociales au debut du siècle". Les Temps Modernes, 496/497, pp.53-92.

WEBER, Max (t 958) - The Protestant Ethic and the Spirit of Capitalism. New York, Chartes Scribner's Sons. 


\section{O "ADEUS AO PROLETARIADO" DE GORZ, VINTE ANOS DEPOIS}

JOSUÉ PEREIRA DA SILVA

O livro de Gorz não perdeu seu interesse, argumenta o autor. Ao examinar por que o trabalho não mais pode servir de fundamento à integração social e ao sustentar que somente uma política de redução do trabalho pode responder à revolução tecnológica em curso, Gorz dá maior nitidez aos termos do debate e oferece condições para aprofundá-lo.

\section{GORZ'S "FAREWELL TO THE WORKING CLASS" AFTER TWENTY YEARS}

It is argued that Gorz's book has not lost its interest. By examining why work is no longer a foundation for social integration and by holding that only a policy of work reduction could be able to face the current technological revolution, Gorz's analysis allows for a clearer understanding of the terms of the debate. 